DOI: 10.14451/2.137.19

\title{
БУДУЩЕЕ ПРАВА: УСТОЙЧИВОСТЬ СИСТЕМЫ ИЛИ СМЕНА КАЧЕСТВА
}

\author{
(c) 2019 Павлушина Алла Александровна \\ доктор юридических наук, профессор \\ Самарский государственный экономический университет, Россия, Самара \\ (c) 2019 Лошкарев Андрей Викторович \\ кандидат юридических наук, доцент \\ Самарский государственный экономический университет, Россия, Самара \\ 2482337@mail.ru \\ (c) 2019 Шлиньков Арсений Анатольевич \\ студент \\ Самарский государственный экономический университет, Россия, Самара
}

Трансформация, по существу, есть термин, опосредующий действие философского закона перехода количественных изменений в качественные. Очевидно, что в современных правовых системах идет активное накопление количественных признаков, которые рано или поздно вызовут к жизни новую стадию в развитии права. Какой интерес является актуальным - обеспечение устойчивости существующей системы или подготовка к означенному переходу в новое качество и ускорение его? Синергетическим параметром порядка выступают в этом случае принципы права. В статье рассматривается ситуация подобного выбора в современном мире.

Ключевые слова: трансформация в праве, переход количества в качество; принципы права; синкретические параметры порядка.

Трансформация, как понятие, безусловно, многозначный термин. Он широко используется как логико-философская основа в самых разных областях знания - от лингвистики до генной инженерии. В самом общем виде его часто определяют как изменение формы или структуры чего-либо. Представляется, однако, что это слишком узкая трактовка. Является ли „транс“-„формация“ только изменением формы? Либо этот термин призван обозначить выход за пределы прежнего качества системы и переход ее к новому качеству?

Очевидно, что мотивами к обозначению происходящих в праве и экономике настоящего времени изменений термином „трансформация“ послужили следующие причины:

1. социальная практика активно указывает на увеличение скорости перемен, период плато в развитии как в области развития социума, так и в реалиях существования правовых систем сменился периодом ускорения перемен, увеличения скорости накопления изменений, не свойственных существующему качеству систем;

2 . ученый не может не задаваться вопросом к чему это ведет - к смене ли только формы правовой системы или к принципиальному из- менению ее качества?

Полагаем, термин „трансформация“ затрагивает не только форму. В своем действительном смысле „транс-формация“ опосредует известный философский закон перехода количественных изменений в новое качество, перехода границы одного качества в другое. Такое обозначение происходящих в праве и обществе процессов означает, что мы стоим на пороге качественной смены систем права, экономических систем мирового и регионального масштаба. Либо, употребляя этот термин, мы утешаем себя тем, что мир находится в затяжном процессе перехода, вновь в „переходном периоде“, в „транссостоянии“ - состоянии между двух качеств. Как справедливо отмечает Г. Хакен: „Мы живем в непрерывно меняющемся мире. Постоянно происходит одновременное рождение новых идей и смерть прежних. Перед нами головокружительная картина бесконечных изменений, характеризуемая собственной динамикой...“ [1]

Интересным и весьма любопытным в этом смысле является документ, о котором подробно сообщали и российские СМИ, а именно - Доклад национального разведывательного Совета США „Глобальные тренды: парадокс прогресса“, под- 
готовленный офисом директора национальной разведки в январе 2017 года для представления в Конгресс США. [2] Не имея своей целью давать политические оценки названному документу, считаем интересным отметить, что весь он, имея в виду его прогностический характер, не утверждает новое качество мирового порядка, а указывает на количественные изменения в экономике, праве, политике мирового сообщества. Доклад изобилует утверждениями о „возрастании напряженности“, „уменьшении прироста производительности труда“, „понижении темпов экономического роста“, „увеличении бедности, увеличении риска возникновения конфликтов, увеличении числа и сложности проблем“ и т.п. Серьезный документ, составленный лучшими прогностическими научными коллективами Америки указывает на нахождение мира в состоянии накопления новых, далеко не позитивных обстоятельств общественной жизни.

Представляется, что в настоящее время очевидным является синергетический эффект улитки. В эволюционных учениях о времени этот эффект называют формулой спирали. В каждом спиральной цикле ход эволюции имеет ускоренный характер на фоне прошлого. Как говорят исследователи соответствующих проблем, „ на этапе Европейского цикла эволюция выжала до отказа педель скорости“ [3].

Социальные трансформации, произошедшие за последние годы, поистине колоссальны. Это и развал империй, и зарождение новых, происходящие иногда без оглядки на государственные границы и суверенитеты; крушение социальных и экономических систем; качественный скачок в развитии технологий, ставших также во многом над государственными границами и несущими в себе зародыш нового мироустройства.

Вопрос, который стоит в настоящее время перед мировым сообществом, заключается в следующем: Что является желательным - закрепление найденных и закрепленных ранее международными договорами и соглашениями параметров порядка или признание, принятие и утверждения новых стандартов, приходящих в право явочным путем? Иными словами- каков господствующий социальных интерес: обеспечивать устойчивость системы, приводя ее правовыми методами к соблюдению параметров порядка или подготовка к обозначенному синергетическому переходу системы в новое качество и, возможно, ускорение его?
Полагаем уместным применение выводов синергетики, как философско- методологической основы, для анализа прогностического развития правовых систем. Как справедливо отмечает основатель синергетики Г.Хакен, определенно указывающий на применимость синергетических моделей к социальной реальности: “Как показано математически в синергетике, во многих случаях поведение системы, близкое к таким точкам неустойчивости, может зависеть от поведения очень немногих переменных, можно даже сказать, что поведение отдельных частей системы просто определяется этими немногими факторами. Эти факторы называются параметрами порядка...Параметры порядка играют доминирующую роль в концепции синергетики. Они «подчиняют» отдельные части, т.е. определяют поведение этих частей. Связь между параметрами порядка и отдельными частями системы называется принципом подчинения. С определением параметров порядка практически описывается поведение системы. Вместо того, чтобы описывать поведение системы посредством описания отдельных ее частей, нам нужно иметь дело или описывать поведение только параметров порядка. Другими словами, мы получаем здесь огромное информационное сжатие“" [4].

Очевидно, что в праве параметрами порядка призваны выступать и выступают принципы права. Они всегда во всех международных и межгосударственных отношениях, равно как и во внутреннем законодательстве, являются своеобразной кристаллической решеткой, порядком связывания права в систему, они определяли ее основные качества. В настоящее время не существует международного договора о названных категориях, охватывающего все государства мира, как не существует и мирового суверена, способного обеспечить его исполнение, а соответственно и придать существующей системе устойчивость. Однако, договоры такого рода, признаваемые значительным количеством государств, хотя бы декларативно, существуют.

Базовыми, весьма значимыми международно-правовыми актами в этой сфере, зафиксировавшими межгосударственный компромисс по установлению соответствующих параметров в праве, являются Всеобщая декларация прав человека, равно как и Европейская Конвенция о защите прав человека и основных свобод. Всеобщая декларация прав человека в окончательной 
редакции была поддержана 48 странами (из 58 тогдашних членов ООН) на 183-м пленарном заседании Генеральной Ассамблеи Организации Объединённых Наций в Пале де Шайо (Париж) 10 декабря 1948 г. Европейская конвенция имеет 47 стран-участниц, что очевидно является представительной выборкой в обозначении правовых приоритетов и стандартов в мире. Известно, что Конституции многих стран мира также основаны на соответствующих принципах и называют их. Как справедливо отмечает Фридрих фон Хайек: „Людей ведет к согласию и связывает в устойчивую социальную структуру то, что на непохожие в деталях ситуации они отвечают согласно одним и тем же абстрактным правилам.“ [5]

Очевидно, что в мире в последние десятилетия идет лавинообразно накопление явлений иного качества, чем заложенные в этих документах принципы. Какой из принципов не возьми, в социальной реальности присутствуют массовые нарушения их. Иногда так называемые „отступления от общепризнанных норм и прав человека“ кажутся или представляются частными. Однако, стоит обратить внимание на то, что при их количественном накоплении неизбежным является возникновение нового качества правовых систем, массовые нарушения и отступления от параметров порядка ведут к трансформации правовых систем, к замене старого, признаваемого многими государствами в качестве искомого правопорядка неким новым.

K глубокому сожалению следует констатировать, что новостные рассылки свидетельствуют о плачевном состоянии в части правореализации и соблюдения правовых параметров порядка. Право на жизнь, сформулированное в вышеуказанных документах, как невозможность умышленного лишения жизни, иначе как в установленных законом случаях, очевидно, нарушается любого рода войнами, а они идут в целом ряде регионов. А ведь в соответствии с Статьей 28 Всеобщей Декларация „Каждый человек имеет право на социальный и международный порядок, при котором права и свободы, изложенные в настоящей Декларации, могут быть полностью осуществлены“. Очевидно, что все они невозможны в условиях войны. Ситуацию в мире в этой части отнюдь нельзя назвать благополучной, а ведь политика при всей ее взаимосвязи с экономикой есть продукт человеческого сознания и человеческого социального и политиче- ского поведения.

Многочисленные сообщения СМИ о пытках в судебно-исполнительных системах, о политических убийствах, множественные акты военной агрессии с человеческими жертвами, неизбежными в таких случаях, участившиеся сообщения о самоубийствах из-за бедности есть не что иное как массовые нарушения права на жизнь.

Не прекращающаяся информационная война с постоянно появляющимися в СМИ обвинениями в дезинформации, хакерских атаках, с ее пропагандистскими приемами не уменьшилась, а значительно приросла в последнее десятилетие, наглядно демонстрируя названное спиральной ускорение в увеличении эпизодов нарушения права на свободу мысли.

Противостояние юрисдикций, когда взаимоисключающими являются решения международных и внутригосударственных судов, как, например, в сфере спортивного права, делающие возможным „признание лица олимпийским чемпионом на территории России“ [6], являющиеся абсурдными по существу, свидетельствует о коррозии в праве на справедливое судебное разбирательство.

В соответствии со Ст. 13 Всеобщей Декларации “Каждый человек имеет право свободно передвигаться и выбирать себе местожительство в пределах каждого государства. Каждый человек имеет право покидать любую страну, включая свою собственную, и возвращаться в свою страну“. Украина, введя военное положение, запрещала выезд российским мужчинам от 16 до 60 лет.; в России более миллиона человек являются невыездными на основании актов приставов-исполнителей, известна миграционная ситуация на границах США и Мексики, равно как и миграционный кризис в странах Европы. Уровень визовых ограничений и состояние санкционных войн, в том числе в отношении персоналий, очевидно не есть реализация этого принципа. Попытки ограничить интернет государственными границами, массовые блокировки в сети, есть ограничение в действии Ст.19. Всеобщей Декларации, в соответствии с которой „Каждый человек имеет право на свободу убеждений и на свободное выражение их; это право включает свободу беспрепятственно придерживаться своих убеждений и свободу искать, получать и распространять информацию и идеи любыми средствами и независимо от государственных границ“. 
Как отмечают обозреватели, „крупные хранилища данных, принадлежащих частным корпорациям -гигантам,- лакомая добыча для хакеров. Они могут украсть информацию для перепродажи или шантажа, а также передать ее другим злоумышленникам. Сами компании бывают нечисты на руку: они обменивают и продают информацию о пользователях, не ставя их в известность.“ [7]

В качестве примера приводят тайную сделку между MasterCard и Google: IT-гигант следил за тратами пользователей для проверки эффективности рекламы [8]. Или иная информация: Социальный сервис обмена знаниями Quora сообщил на сайте компании о массовой утечке персональных данных. В результате взлома в сеть попала личная информация 100 млн. аккаунтов, причел утекли как общедоступные, так и закрытые данные [9]. Налицо не просто массовое, а глобальное нарушение принципов личной тайны, невозможности произвольного вмешательства в нее. И ведь подобных ситуаций фиксируется в мире не штучно. Вряд ли при подобном масштабе можно говорить о полноценном действии названного принципа в мировых правовых системах. Параметр порядка не работает.

В качестве противовеса обычно звучит утверждение, что названные декларативные установления не могут быть и не являются безграничными, каждый из них может в разумной мере быть ограничен в интересах здравости и общей безопасности. Представляется, однако, что многие публичные субъекты мировой политики слишком далеко отодвинули границу общечеловеческих ценностей, усиливая режимы противоправными запретами.

В этом смысле следует согласиться с подобным подходом к оценке каркаса права, который был представлен в выступлении главы дипломатии ЕС Федерико Могерини. Фиксируя ситуацию, она отметила: „Боюсь, сегодня мы вынуждены признать, что мировой порядок до сих пор по настоящему не установлен. Более того, в современных условиях есть реальная опасность господства закона джунглей над верховенством закона. Сомнениям сейчас подвергают те же международные договоры, сто привели к концу холодной войны“. Вместо строительства нового порядка, приходится тратить огромные силы на предотвращение демонтажа существующих правил.“ [10]

Если иметь в виду действительный смысл понятия мировой порядок, опуская растиражированный его пропагандистский смысл, речь фактически и идет о том, что мы находимся в точке бифуркации, признаки нового качества нарастают, что основополагающие принципы права попираются глобальными общемирового масштаба массовыми нарушениями. Очевидно, что в мире идет активное количественное накопление несоответствующего параметрам порядка нового качества. „Конкуренция параметров порядка и упорядочивание системы за счет доминирования одного из них характерна для многих социальных и психологических процессов - таких, как общественные настроения, мода, принятие правил и обычаев или распознавание образов.“ [11] Однако не встает ли исключение выше правила, приобретая тем самым не только самодостаточный характер и перерастая, таким образом, в новый мировой порядок, новое правило, принцип, параметр порядка. Как далеко все мы отстоим от точки бифуркации, когда, невзирая на международные хартии и договоры, мир перейдет в иную, невозвратную по названным показателям стадию?

Какова роль в осмыслении всех описанных выше процессов мировой гуманитарной науки?

Показательным в этом смысле представляется социологический вывод, принадлежащий американскому психологу Соломону Э. Элу. Не обращаясь к самому ходу эксперимента, (в нем предлагалось оценить длину трех представленных отрезков группе из непосвященных и посвященных участников, заведомо сообщающих неверный ответ, и направлен он был на выявление самостоятельности суждений его участников), приведем сам вывод. , Из каждых десяти испытуемых двое не поддавались на провокации и давали ответ, соответствующий их личному восприятию; двое присоединялись к чужому мнению только один-два раза из десяти; шестеро же оставшихся, соглашаясь с большинством, сообщали экспериментатору в качестве собственных заведомо неверные ответы. Это означает, что даже в безобидных вопросах... значительная часть людей предпочитает присоединяться к мнению большинства, даже в тех случаях, когда это мнение очевидно для них ошибочно“ [12].

Предназначение гуманитарной науки при осмыслении будущего права - в осмысленном следовании параметрам порядка, заложенным во Всеобщей Декларации. В праве на свободу информации при формировании мнения. В 
максимально возможном количестве и спектре источников информации и в профессиональном их восприятии. Только юридическое понимание характера нарушений параметров порядка дает возможность указывать общественному мнению на их избыточность, их не необходимый характер. На нарушения, обслуживающие лишь политические и экономические потребности отдельных групп, раскачивающие общепринятые параметры порядка и ведущие нас в мир антиутопии, где в точном соответствии с законами диалектики мы можем столкнуться с их прямой противоположностью.

\section{Библиографический список}

1. Г. Хакен Тайны природы. Синергетика: наука о взаимодействии. М.- Ижевск: Институт компьютерных. 2003.-320 C.; C. 204

2. Ларина Е., Овчинский В. Преступность, терроризм и технологии будущего (по материалам доклада разведки США) // spkurdumov. ru

3. Николаев А. В. Время. Теория. Часть 1. Direct Media. Х Раздел. Параграф 6. Цифровая спираль// books.google. de.

4. Хакен Г. Можем ли мы применять синергетику в науках о человеке?“/ Синергетика и образование. // spkurdumov.ru

5. Хайек ф. Ф. Право, законодательство и свобода. М, 2006-644 С. С.180

6. Зубков А. Из интервью pervonovosti ru) // pervonovosti ru 2018

7. Кадочникова С. Интернет потерпел крах. В сети бушуют цензура и блокировки, но есть способ спастись.// https: m.lenta.ru/articles/2018/09/24/dweb/

8. Там же

9. Масштабная утечка в Quora./https://ain.ua/2018/12/04/quora-bolshaya-utechka/

10. Могерини Ф Из выступления в Университете Гарварда 03.12.18 // mt.360tv.ru

11. Хакен Г. Тайны природы. Синергетика: наука о взаимодействии. С. 194

12. Там же 